\title{
Most-favored-nation clauses in commercial contracts: legal and economic analysis and proposal for a guideline
}

\author{
Gönenç Gürkaynak ${ }^{1,2,3} \cdot$ Ayşe Güner ${ }^{1}$. \\ Sinan Diniz ${ }^{1} \cdot$ Janelle Filson $^{4}$
}

Published online: 27 October 2015

(C) The Author(s) 2015. This article is published with open access at Springerlink.com

\begin{abstract}
The prevalent use of "most favored nation" (MFN) clauses in commercial agreements has garnered significant attention in the economics and legal literature and by practitioners and enforcement agencies. From an antitrust standpoint, there is a strong consensus that while MFN provisions can lead to procompetitive outcomes or at least play a competitively neutral role, they may also result in competitive harm and a loss of consumer welfare. Therefore, US and EU enforcement agencies and courts have held that MFNs should be reviewed on a case-by-case basis, considering the specific characteristics of both the contractual provision and the industry. While a case-by-case approach is valid, it is not ideal from a variety of standpoints: that of the competition authorities seeking to make best use of their limited resources and that of practitioners seeking to advise their clients. Accordingly, published guidelines on the use of MFNs, containing presumptions and safe harbors, would be both efficient and useful. The paper argues that it would increase the efficiency and accuracy of antitrust enforcement if one of the leading competition authorities issued MFN guidelines. The paper suggests a set of presumptions and safe harbors that should be included in any such guidelines.
\end{abstract}

Keywords Most favored nation clause $\cdot$ MFN - Most favored customer clause MFC $\cdot$ Best price clauses · Price parity clauses

JEL Classification $\mathrm{K} 21 \cdot \mathrm{L} 41 \cdot \mathrm{L} 42$

Ayşe Güner

ayse.guner@elig.com

1 ELIG, Attorneys-at-Law, Istanbul, Turkey

2 Bilkent University Law School, Ankara, Turkey

3 Yeditepe University Law School, Istanbul, Turkey

4 New York, USA 
The so-called most favored nation (MFN) or most favored customer clauses (MFC) are essentially agreements between a supplier and a customer whereby the supplier promises the customer that it will grant it equally favorable terms as granted to any other customer. ${ }^{1}$ MFNs are often employed in vertical relationships between firms involved in complicated distribution chains across many sectors, including energy, insurance, health, film distribution, retail goods and many more. ${ }^{2}$

Despite their various efficiency generating functions, MFN provisions can nevertheless lead to competitive harm, loss of consumer welfare and higher consumer prices. As will be discussed more extensively below, the potential competitive concerns associated with MFNs generally fall into three categories: (1) reduced price competition, (2) facilitating collusion between competitors, and (3) exclusionary effect on rivals at the buyer level.

To date, while there have been a number of visible antitrust cases surrounding MFNs, there is little concrete legal guidance available on the day-to-day use of MFNs and no guidelines adopted in any of the jurisdictions. Given the complex nature of the effects of MFN clauses on competition, analyzing the impact of MFN clauses can pose challenges for both regulatory authorities and businesses and practitioners. One way to deal with the complex landscape presented by MFN arrangements would be for competition authorities or courts to undertake a separate rule of reason analysis with respect to each and every case. However, proceeding purely on the basis of case law, without the help of secondary legislation, has several important disadvantages, and in our view, constitutes a an impractical alternative. To that end, this paper argues that competition authorities seeking to make the best use of their limited resources and the available evidence, and practitioners seeking to advise their clients in the most effective manner, would benefit from a guideline that sets out the different forms of MFNs along with guidance in terms of presumptions and safe harbors regarding circumstances in which MFNs are more or less likely to lead to anticompetitive harm from the point of view of the enforcement agency.

This paper first argues for the need for a guideline in comparison to the case-bycase approach observed in most jurisdictions, and proposes a structure of useful elements such a guideline should cover. Within the context of a model guideline, we then introduce a theoretical discussion of the potential positive and negative economic effects of MFN clauses on competition, drawing on the existing economic literature and antitrust case law to illustrate the relevant effects, as we believe it is important for a guideline to offer a sound theoretical background to provide context for more specific guidance. We then identify certain market dynamics or contractual characteristics which present a strong risk of anti-competitive effects and possible presumptions of illegality in order to provide more specific guidance and greater legal transparency. Finally, the paper suggests a set of safe harbors that should be included in any such guideline.

Throughout the paper, we conduct our analysis by distinguishing between two types of MFN clauses. As provided above, "traditional" MFN clauses are

\footnotetext{
1 As MFNs and MFCs are of the same nature, this article refers to these types of clauses as MFNs.

2 Particularly, various academic sources have noted the prevalence of MFN clauses or similar structures in long-term energy contracts see Crocker and Lyon (1994), Mulherin (1986), Canes and Norman (1986).
} 
provisions in which a seller promises the recipient that it will provide the best price or the most favorable sale conditions. Much of the recent antitrust attention has focused on a similar but slightly different contractual structure. In the case of the socalled retail $\mathrm{MFNs}^{3}$ or platform MFNs, ${ }^{4}$ a seller who markets products through a platform guarantees the platform operator that it will not offer the same products for a cheaper price or more advantageous terms through another platform. As will be discussed further below, in only the last few years, retail MFNs have been scrutinized by the US Justice Department, the European Commission, as well as the national competition authorities of various EU member states in a variety of sectors such as online hotel bookings, online sale of e-books, and price comparison websites for motor insurance.

Unsurprisingly, retail MFN provisions have usually been utilized in combination with an agency model where the suppliers remain in control of the prices offered through the platform, and the platform realizes its revenues through taking a commission on the sale. ${ }^{5}$ In our analysis of retail MFNs, we will generally proceed under the assumption of an agency model.

\section{The need for a clear guideline for MFN clauses}

\subsection{The advantages of a guideline and a potential structure}

The US and European enforcement agencies have so far reviewed MFNs on a caseby-case basis. However, a case-by-case analysis of MFNs creates challenges for businesses and legal practitioners due to the necessity for extensive legal research created as a result, and the limitation of the guidance to the issues presented in the relevant cases.

Businesses that are engaged in commercial negotiations with respect to a wide variety of parameters have a pressing need to reach business decisions quickly and the widespread use of MFNs in numerous industries shows that they are a common tool that businesses rely upon. To that end, gleaning through isolated decisions in order to come to a conclusion about the legality of a given business decision may translate into delays which increase transaction costs and may even threaten the successful conclusion of deals which are under intense time pressure. While it is understood that businesses will proceed under legal advice from professional practitioners, a singular guideline which sets forth clear criteria (such as, safe harbors, presumptions of illegality and primary competition law concerns, etc.) will also offer distinct advantages for the legal practitioner in terms of timing and cost. Indeed, the existence of a guideline would also make it easier for practitioners to

\footnotetext{
3 A retail MFN or a retail price MFN seems to be the more common terminology, used inter alia by the European Commission, as well as commentators such as Johnson (2014).

4 This terminology is used by Boik and Corts (2013).

5 A supplier and a platform could also work through a resale model where the platform purchases the relevant products from the supplier, paying a wholesale price, and resells them for the prices it independently determines. However, this model would make a retail MFN difficult to observe for a supplier as it no longer has control over retail prices.
} 
spot possible legal issues in advance. This is particularly true in civil law settings where legal practitioners are used to proceeding primarily on the basis of legal instruments rather than case law.

Even in the case of advanced competition law regimes, such as the US and EU, the number of decisions concerning (traditional and retail) MFN clauses are relatively few, despite the recent and increasing level of attention on retail MFNs in particular. Furthermore, the precedential value of some of the existing cases is complicated by the fact that they have been resolved by commitments or consent decree procedures which do not result in a formal finding of a violation. For instance, in the case of the EU, past enforcement efforts concerning MFN clauses have ceased without formal proceedings due to voluntary elimination of the relevant clauses, ${ }^{6}$ or, as in the case of the $e$-books case, in a commitment decision, which also does not constitute a finding of a competition law infringement even though it is binding.

The preparation of a guideline will also benefit competition authorities as, through a guideline, the case handlers of competition authorities will themselves have access to clear-cut criteria which will minimize the chances of investigations concerning cases that do not present competition law concerns, allowing the competition authority to conserve its resources for more important cases and allow for efficiency in case load management.

The preparation of a guideline which offers the opportunity to highlight the relevant competition law issues in a complete manner and in an ex ante basis therefore seems to be the much more advantageous alternative from an ideal antitrust compliance/enforcement perspective compared to leaving the treatment of MFN clauses to the eventual unfolding of case law. This is because the preparation of a guideline would (1) reduce legal delays and transaction costs through providing guidance on potential legal issues in a manner which can be easily accessed, (2) reduce legal uncertainties especially for relatively young competition law jurisdictions where the case law may not yet be sufficiently developed, and (3) allow competition authorities to conserve their resources by eliminating non-problematic cases easily as a result of safe harbors identified by the relevant guideline.

In line with the need for greater predictability and a singular source of information which is both comprehensive and easily accessible, we argue that a guideline should provide the following main elements:

1. Definitions of restrictions encompassed within the concept of MFN;

2. Theoretical discussion of general antitrust concerns posed by MFN clauses and market dynamics or contractual characteristics which present a strong risk of anti-competitive effects and possible presumptions of illegality;

3. Efficiencies and justifications which may be created by MFN clauses and particular contexts where they may be pro-competitive;

4. Safe harbors which set out under which conditions the presence of MFN clauses are unlikely to lead to any competition law concerns and therefore should be presumed legal by the courts and/or competition authorities.

\footnotetext{
${ }^{6}$ These cases include Pay TV (2004), Ruhrgas/Gazprom (2005), Theater Digitalization (2011).
} 
For the sake of clarity, these elements should not be thought of as an exhaustive list, but as the essential terms of a model. Based on the points of convergence in existing case law in different jurisdictions and the academic literature on MFN clauses, below we propose the content of the various issues outlined in the above headings.

One legitimate inquiry for jurisdictions that follow the EU approach and exempt certain vertical agreements entirely from the application of the competition law would be whether the MFN clauses benefit from the Vertical Block Exemption Regulation ("VBER") (or from a similar vertical block exemption regulation adopted under local law), and if so, whether there would still be a need for an MFN guideline. For this reason, before we provide our recommendations on the content of a model guideline on the MFNs in the following section, we initially provide some discussion on whether MFN clauses should benefit from the VBER, and if so, how the model MFN guideline should interplay with the VBER (or a similar block exemption regulation formulated for vertical agreements).

\subsection{Would MFN clauses benefit from regulations such as the Vertical Block Exemption Regulation?}

In jurisdictions, such as the EU, vertical agreements that satisfy certain criteria can be exempted from the application of the competition law. Take, for instance, the VBER that is currently enforced in the EU. So long as the parties to the agreement operate at different levels (one supplier and the other purchaser) of a supply chain and so long as their individual market share in the relevant market does not exceed a certain threshold (i.e. $30 \%$ ), VBER would allow the parties' agreement to be exempt from the application of Article 101(1) of the Treaty on the Functioning of the European Union ("TFEU"). Under the VBER, hardcore restrictions, such as resale price maintenance ("RPM"), would not be exempted.

As MFN clauses are essentially vertical restraints, they are theoretically subject to the VBER and the Guidelines on Vertical Restraints. Article 2 of the VBER provides that "pursuant to Article 101(3) of the Treaty and subject to the provisions of this Regulation, it is hereby declared that Article 101(1) of the Treaty shall not apply to vertical agreements." Given that the above provision provides a blanket exemption for vertical agreements subject to certain exceptions, vertical agreements between a supplier and the purchaser of the relevant good or service which contains an MFN clause would be exempted from the scope of Article 101(1) of the TFEU subject to the provisions of the VBER. ${ }^{7}$ Against the foregoing, it can be argued that as vertical restrictions, MFN clauses stand to benefit from the block exemption provided by the VBER. On the other hand, as of yet, this conclusion has not been confirmed in any Commission decision.

\footnotetext{
7 With respect to scope, Article 3 of the VBER provides that the block exemption is only applicable to those agreements where "the market share held by the supplier does not exceed $30 \%$ of the relevant market on which it sells the contract goods or services and the market share held by the buyer does not exceed $30 \%$ of the relevant market on which it purchases the contract goods or services." Furthermore, pursuant to Article 2 (4), VBER does not apply to vertical agreements between competitors.
} 
Similarly, neither the VBER nor the Guidelines on Vertical Restraints provide specific guidance concerning MFN clauses. In fact, the VBER does not mention MFN clauses at all, while the Guideline on Vertical Restraints includes only the following reference in paragraph 48 which concerns RPM:

Similarly, direct or indirect price fixing can be made more effective when combined with measures which may reduce the buyer's incentive to lower the resale price, such as the supplier printing a recommended resale price on the product or the supplier obliging the buyer to apply a most-favored-customer clause. The same indirect means and the same 'supportive' measures can be used to make maximum or recommended prices work as RPM.

While the above language notes the RPM-related competitive concerns arising out of a supplier obliging the buyer to apply a MFC clause, it does not shed any light on the treatment of the use of MFN clauses in and of themselves.

It has been suggested by the German Federal Cartel Office ("FCO") that MFNs could potentially be considered within the scope of Article 4(a) of the VBER concerning resale price maintenance, and therefore as a hard-core restriction that does not benefit from the block exemption, though this was ultimately left open (FCO 2013c, para. 181 et seq.). In this respect, the FCO acknowledged that the restrictions in question are not covered by a strict reading of the wording of Article 4(a) (FCO 2013c. Para. 183) as the clauses do not restrict the resale price of a buyer. Nevertheless, the FCO argues that the competitive effect of the MFN clauses is similar in character to the vertical price maintenance covered under the relevant article (FCO 2013c. para. 184-185). As the market share of HRS in the relevant market exceeded $30 \%$ and HRS did not benefit from the VBER, the FCO ultimately left open the question of whether MFN clauses are hard-core restrictions.

However, such an interpretation is open to criticism for being too expansive as MFN clauses do not necessarily limit the resale price of the buyer in a vertical relationship but in fact impose a pricing limitation on the supplier. Furthermore, an MFN clause does not formally restrict the ability to discount but merely obliges a supplier to offer the same discount to the buyer (although this obligation can create an incentive not to offer discounts).

The FCO also elaborated on its stance towards the use of retail MFNs in its "Vertical Restraints in the Internet Economy: Meeting of the Working Group on Competition Law" paper (FCO 2013a) which was published about two months before the HRS decision. In its discussion of MFN and price parity clauses, the FCO emphasizes that MFN clauses reference the prices of competitors, and therefore they go beyond a mere vertical restraint and have a horizontal dimension (FCO 2013a).

In its enforcement history against the use of MFN clauses, the European Commission has taken action against the use of MFN clauses in cases where it deemed that they were being used to facilitate a horizontal agreement or concerted practice (e.g. the e-books case-discussed below), or cases where their use was so widespread that the cumulative effects threatened to create exclusionary effects (e.g. the theater digitalization case-discussed below) or cause the harmonization of commercial terms (e.g. Pay TV 2004). The most recent investigation conducted by the Commission against Amazon, launched in June 2015, also illustrates the 
Commission's stance on MFN clauses. Its probe will arguably also consider whether Amazon's contractual arrangements with publishers lead to the exclusion of Amazon's competitors given that according to the Commission, Amazon is the largest e-books distributor in Europe. The Commission launched the investigation due to Amazon's contractual MFN-type clauses with publishers concerning Amazon's sale of e-books. The press release provides that the clauses allow Amazon: (1) the right to be informed of more favorable or alternative terms offered to its competitors; and (2) the right to terms and conditions at least as good as those offered to its competitors. The Commission will investigate whether "such clauses may hinder the level playing field and potentially decrease competition between different e-book distributors to the detriment of consumers" (Amazon 2015).

Considering the above arguments raised, it is inevitable that MFNs may or may not benefit from VBER (or a similar block exemption regulation formulated for vertical agreements). We argue that in cases where the relevant jurisdiction does not have a block exemption regulation formulated for vertical agreements or that the relevant authority finds that MFNs are hard-core restrictions that are not exempt by the relevant block exemption regulation, then the model guideline on MFNs becomes ever more useful. Needless to say, however, as a number of jurisdictions including the EU have block exemption regulation formulated for vertical agreements, the more important question is whether in case the MFN clauses benefit from the vertical exemption regulation, how would that interact with the model MFN guideline.

In case where the MFNs were to benefit from the VBER, the guideline could for instance provide the circumstances in which MFNs benefit from the VBER, and distinguish cases that do not benefit from the VBER. An alternative could be that the vertical exemption regulation could be amended to clarify the recent case law on the MFNs and take a position on the types of MFNs that would be exempt by the vertical block exemption regulation, and distinguish cases, such as, for example, MFN-plus arrangements, that may not benefit from the block exemption.

\section{Proposed content for a model guideline}

\subsection{Definitions of MFNs}

As provided above, an MFN clause has been traditionally defined as an agreement by which the seller agrees that the buyer will receive terms that are at least as favorable as those offered to any other buyer (Stenger 1989; Dennis 1995). However, with the popularization of retail MFNs in multi-sided markets, a different structure has been added to the rubric of "MFNs." Indeed, in many cases commentators have not distinguished between traditional MFNs and retail MFNs despite the differences in structure and therefore certain differences in terms of effect on competition. ${ }^{8}$

The so-called retail MFN clauses used in the e-books investigations (i.e. guarantees by suppliers to platform operators that the relevant supplier shall not

\footnotetext{
${ }^{8}$ For example, Salop and Scott Morton reference the clauses used in the e-books case simply as MFNs without making an MFN/retail MFN distinction (Salop and Scott Morton 2013).
} 
offer the relevant goods for more advantageous terms in rival platforms) do not fit the narrow description provided above but have been embraced under the rubric of "MFN." Similarly, best price guarantees across sellers (also known as "meeting the competition clauses" or "best price clauses") have sometimes been referred to as MFNs. ${ }^{9}$

The presence of potentially divergent terminologies makes it a helpful attribute for a guideline to define the concept of "MFN" clause and its scope at the outset. While a guideline could simply focus on the traditional and retail MFNs, as we do below, a guideline could also embrace a much wider scope and also explain similar provisions which "reference prices of rivals" such as across-seller price guarantees, English clauses, etc. Either way, to preserve the conceptual clarity and prevent the conflation of the competitive effects of different types of provisions, the definitions of the examined provisions should be clear.

\subsection{General antitrust concerns posed by MFN clauses and market dynamics or contractual characteristics which present a strong risk of anti- competitive effects}

\subsubsection{General discussion of anti-competitive concerns posed by MFNs}

As Dennis (1995) points out, MFN clauses do not merely affect the relationship between the buyer and the seller: "By implicating the commercial relationships of other buyers, MFN clauses can indirectly affect the price structure of the entire marketplace as well as everyone in it" (Dennis 1995, p.77). Fiona Scott Morton, formerly of the U.S. Department of Justice, later expanded on this concept in defining a category of "Contracts that Reference Rivals," which have a potential to harm consumers and competition, "particularly when they involve firms with market power” (Scott Morton 2012, p.3).

MFN clauses cannot be viewed statically and independent of the effects they may have on the rest of the market. As a result, it is important for a potential guideline to provide a sound theoretical background regarding the relevant risks for effective guidance.

The potential harms that can be wrought by MFNs generally fall into three categories: (1) reduced price competition, (2) exclusion, and (3) facilitating collusion. The above three concerns arise for both traditional MFNs and retail MFNs, though as will be discussed below, the relevant mechanisms through which this effect is realized may change.

\section{Reduced price competition}

Baker and Chevalier (2013) describe how MFNs can operate as a "tax" on pricecutting by the seller. The MFN operates so that any price-cutting by the seller

\footnotetext{
9 For example, Crocker and Lyon (1994) refer to across-seller best price guarantees as three-party-mostfavored-nation-guarantees (3PMFN) and includes both traditional MFNs (referred to as two-party-mostfavorite nation-clauses (2PMFN) and 3PMFNs in the following discussion of rationales for the use of MFNs. See also Jacobson and Weick (2012).
} 
anywhere in the market becomes more expensive, because it must also cut the prices to the buyer with the MFN. The seller may well lose more profit by entering into an agreement with a small buyer at a low price than by not engaging with that buyer at all or by offering only a higher price. The same effect has been described in other words by a variety of commentators: Cernak and Chaiken (2013) describe it as "price stickiness" (reluctance by the seller to compete on price, which increases with the number of MFNs) (Cernak and Chaiken, p.2); Jacobson and Weick (2012) refer to "stabilizing prices at elevated levels" (Jacobson and Weick 2012, p. 6); and Dennis (1995) refers to "setting a price floor" whereby "no one is able to obtain a better price... than the dominant [buyer]" (Dennis 1995, p. 80).

The ability of MFN clauses to stifle price competition is magnified when the relevant MFN provision is retroactive. This is because in this scenario, a discount to one buyer would have to be matched not only with respect to contemporaneous buyers but also past purchases, resulting in a particularly high cost associated with discounting (Salop and Scott Morton 2013). The same is true where an MFN clause includes an additional penalty, such as paying the buyer with an MFN several times the difference between the price received and a better price offered to another customer.

Scott Morton (1997) provides empirical evidence of how traditional MFNs dampen price competition and raise prices. The relevant study examines the effects of the adoption of an MFN protecting Medicaid in regard to medical reimbursements through the Omnibus Budget Reconciliation Act of 1990. She finds that, as a response to the shift in policy, the average price of a branded drug facing generic competition rose by about $4 \%$ (Scott Morton 1997, p. 288). With respect to the prices of generic pharmaceuticals facing competition from branded products, she finds that "those in concentrated markets, with large package sizes and high sales to Medicaid, had significant price increases" (Scott Morton 1997, p. 289). ${ }^{10}$ As noted by Aguzzoni et al. (2012), not only do Scott Morton's result demonstrates an increase in price, but also a correlation between price increase effects and characteristics which would incentivize such an increase under theoretical models. These characteristics include a high share for the protected buyer (e.g. Medicaid), high price dispersion before the introduction of the MFNs and large package sales which are likely to have lower unit prices which would make it more likely for the MFN to kick in (Scott Morton 1997, p. 279-280; Aguzzoni et al. 2012, p. 65-66).

Competitive concerns arise in a similar way for retail MFNs. Assume, for example a platform that tries to undercut the competing dominant platform by including cheaper offers on its own platform. Without the retail MFN, it could strike a bargain whereby it accepts a lower commission on the offer and the supplier in turn offers a lower price in the relevant platform without sacrificing its own profit. However, where other platforms are protected by a retail MFN, the supplier could lower its price in one platform only where it also lowers them in the protected platforms regardless of whether they have reduced their commissions, likely sacrificing a significant amount of profits.

\footnotetext{
10 The distinction between generic and branded drugs in the analysis stems from the fact that generic drugs were not covered within the scope of the MFN protection, even though they still faced a price cap in the amount of $90 \%$ of their average price (Scott Morton 1997, 275).
} 
The potential for retail MFNs to dampen price competition has been a major element of the recent antitrust scrutiny of such clauses. In its investigation of the online hotel booking platform, HRS, the FCO stated: "The freedom of price setting of the hotels and that of the hotel portals is equally negatively affected: The MFN clauses prevent the hotels from offering rooms at lower prices, and for the [hotel portals] there is no economic incentive for charging lower commissions" (FCO 2013c. para 186). HRS offered brokerage services to hotels against a commission based on the rooms booked via the website, i.e. worked under the agency model. HRS had imposed an MFN on the participating hotels that required the hotels inter alia to treat HRS no less favorably than other online booking platforms which prohibited the hotels from offering cheaper rates elsewhere, including the hotels' own website as well as offline channels such as a deal through the hotel's own reception desk (FCO 2013c, para. 173). As a result of these obligations, hotels could not pass on the effect of lower commissions to the customers, even where another agent chose to sacrifice its commission in order to include a better offer.

The FCO reasoned that through preventing the hotels from achieving more flexibility in their pricing, the retail MFNs affected not only the competition between the agents (i.e. intra-brand competition) but also the competition between the hotels (inter-brand competition). According to the antitrust agency, the effect of the retail MFNs was strengthened by the fact that other main online travel agents, Booking.com and Expedia, also used similar retail MFNs (FCO 2013c, para. 174).

Ultimately, the FCO ordered HRS to simply delete the retail MFN clauses from its contractual terms and discontinue their use (FCO 2013b). The FCO also extended its investigation to Booking.com and Expedia based on similar retail MFN clauses.

The United Kingdom's Competition and Markets Authority's ("CMA") Private Motor Insurance Market Investigation Final Report, addressing, among other things, retail MFN provisions between private motor insurance ("PMI") providers and price comparison websites ("PCW") also demonstrates findings regarding the potential of retail MFNs to soften price competition (CMA 2014). In its analysis, the CMA differentiated between the use of "narrow MFN clauses" (ensuring the relevant PCW that the insurance provider will not provide better prices on its own website) and "wide MFN clauses" (ensuring the PCW that the price offered by an insurer in the relevant PCW is at least as good as that offered on any other PCW as well as the insurer's own website).

Particularly, the CMA stated: "We found that wide MFN clauses soften price competition between PCWs in relation to PMI. (...)There is little incentive for a PCW facing a competitor with a wide MFN clause to seek better PMI prices for their retail consumers from insurers because that better price would be passed on to the competitor also." (CMA 2014, para. 58). The CMA also found that wide MFNs would lessen incentives for innovation which lowers operational costs by PCWs as these advantages could not be passed on the customers through cheaper offers and thus enable the PCW to gain market share (CMA 2014, para. 59, para. 8.41). The wide retail MFN clauses were also found to enable the PCWs to squeeze providers for higher commissions as the providers would not be able to respond by increasing the premiums of the offers in the relevant platform (CMA 2014, para. 8.40). The CMA also found evidence of PMI providers turning down offers for reductions in 
price and commission reductions due to wide MFN arrangements in place with other PCWs. (CMA 2014, para. 59).

The CMA also speculated on whether narrow retail MFNs could also dampen competition between PCWs; however, it found that narrow-MFNs were unlikely to have such an effect (CMA 2014, para. 8.54), mainly due to the fact that insurers with significant sales through the direct channel were generally not listed on PCWs and were already unlikely to offer low-price/low-commission offers in PCWs regardless of the presence of narrow-MFNs (CMA 2014, para. 8.51, 8.53). Boik and Corts (2013) study the effect of adoption of retail MFNs (referred to as platform MFNs by the authors) on price levels under an agency model with a single seller selling through one or both of two platforms. The authors find that equilibrium "fees and prices are higher when both platforms have [platform MFN] agreements" (Boik and Corts 2013, p.6). Indeed, according to the authors' model fees and prices with retail MFNs in place turn out to be even higher than those which would be chosen by perfectly colluding platforms (Boik and Corts 2013, p. 6-7). Johnson (2014) also finds that the combination of retail MFNs and the agency model is associated with higher retail prices, and lower consumer surplus (Johnson 2014, p. 16).

\section{Exclusion}

MFNs can also lead to anticompetitive exclusion by raising rivals' costs or by otherwise raising the barriers to entry (see, e.g. Baker and Chevalier 2013, Aguzzoni et al. 2012). By securing an MFN, a buyer will have guaranteed for itself the lowest price available in the market. If the MFN relates to the price of an intermediate good, the clause may raise rivals' costs. That is, if the buyer with the MFN is sufficiently large, it will not be profit-maximizing for the seller to offer a lower price to other market participants, knowing that it will then have to also offer the lower price to the MFN-protected buyer. With higher costs, barriers to entry are higher and the buyer with the MFN has secured or improved its market position. Dennis (1995) describes how "[t]he large book of business that [healthcare] providers enjoy courtesy of the dominant insurer is economically more valuable than realizing an increase in patient volume originating from a competing plan." (Dennis 1995, p.78). In the case of a retail MFN, the buyer will have eliminated the possibility of price competition from its actual or potential competitors. New entrants may be less able to compete with an existing firm without the possibility of competing on price terms.

This exclusionary effect may be particularly significant where suppliers may have reason to offer low prices to financially weaker newcomers in the interest of future business, or where the markets include segments of customers with lesser financial strength for some other reason. The European Commission's Theatre Digitalization preliminary investigation includes a good depiction of this situation.

The relevant case concerns the use of MFN provisions in the contracts between major film studios and contractors that carried out the digitalization of movie theaters. The contractors, referred to as "integrators", purchase the necessary equipment for switching to digital technology and install it in the movie theaters. Under the virtual print fee ("VPF") business model adopted by the major studios, 
the studios would each pay a fee every time a digital film was shown in the specific movie theater, constituting the major part of the integrator's payment. The cinema owner would also contribute to financing the digitalization through an upfront payment to the integrator. The integrator, in turn, would cover its business risk by retaining ownership of the equipment until its payment was completed (Theater Digitalization 2011). The MFN clauses in question guaranteed a studio/distributor the right to benefit from the most favorable terms that the integrator had agreed with any other studio/distributor, including the level of VPF payments made by the studio/distributor.

The Commission initiated a preliminary investigation based on its concern that the widespread use of MFN clauses between the studios and integrators could have the effect of preventing "integrators from signing contracts with distributors of independent/art house films whose business models differed from the major Hollywood film studios" (Theater Digitalization 2011). According to the Commission, the MFN clauses could create an incentive not to offer advantageous terms to independent distributors (who may only be able to take part in the digitalization process under more favorable terms), as the integrator would need to match any discount in its dealings with the major studios. Ultimately, the Commission ended its preliminary investigation without initiating formal proceedings due to the major film studios' willingness to modify their contracts.

The Commission's stance is particularly noteworthy as the relevant MFN clauses were not found to have an anti-competitive purpose. In fact, in its press release concerning the preliminary investigation, the Commission noted that "the stated rationale of these provisions was to ensure that competitors (primarily the other major Hollywood film studios) would not contribute less to the digital switchover while getting equal access to the digital projection equipment in European cinemas" (Theater Digitalization 2011). Despite noting these pro-competitive effects, the Commission nevertheless took the position that the potentially exclusionary effect on independent film distributors was more pressing, and asked the parties to revise their contracts, removing the MFN clause.

The above case constitutes a good example of how an MFN clause can have exclusionary effects through raising the costs of rivals for a key input. Integrators expected to realize the majority of their payments through major Hollywood studios. However, absent the MFN clauses, it would still have been rational for them to price discriminate and offer better terms to those independent distributors with lesser resources (and therefore lower reservation prices) as long as the terms were still profitable from their perspective. The MFN clause would drastically change these dynamics and effectively constitute a "tax" in the amount of foregone profits through accepting lower VPF payments from major studios, likely preventing the transactions with independent studios.

The recent litigation in the US against Blue Cross Blue Shield (BCBS) of Michigan, also illustrates the alleged use of an MFN clause to raise the costs of competitors and thereby gain a competitive advantage. The DOJ filed a complaint in 2010, challenging the MFN clauses used by BCBS. According to the complaint, BCBS was the dominant health insurance company in Michigan, with a $60 \%$ market share. BCBS obtained MFN provisions in its contracts with health providers 
that typically required hospital providers to provide BCBS with lower rates than they offered to any other insurer, which the DOJ referred to as "MFN plus" provisions. The DOJ alleged that BCBS had MFN provisions in its contracts with at least 70 of Michigan's 131 general acute-care hospitals. The complaint described two mechanisms of harm: first, that the providers obtained higher rates in exchange for agreeing to the MFNs, and second, that the MFNs raised the barriers to entry by precluding potential competitors from competing with BCBS on price (specifically, by offering narrower provider networks in exchange for lower prices). The DOJ's complaint survived a motion to dismiss, with the district court holding that the allegations of anticompetitive harm were (at least) plausible (United States v. Blue Cross Blue Shield of Michigan) However, after more than two years of litigation, the Michigan state legislature passed a law banning the use of MFNs by hospitals or health insurers, mooting the DOJ's lawsuit, which was then dismissed. A private claim filed against BCBS in relation to the same claim was settled.

Exclusionary effects on competing undertakings also emerge as an important concern in the case of retail MFNs. As discussed in the above section regarding reduced price competition, a retail MFN hinders suppliers from rewarding platforms charging lower commissions through lower offers on their platform. This in turn prevents new entrants from establishing themselves in the market through a lowcost/low-price model (Oxera 2014).

This effect is confirmed by Boik and Corts 2013 whose economic model predicts that retail MFN provisions may either deter the entry of competitors seeking to adopt a low-cost/low-price model or skew their choice of business model towards a high price/high value one. That said, the authors find that the incentives for entry increase for competitors who already seek to enter based on a high price/high value model due to the high prices which prevail in the market as a result of retail MFNs.

The potential to foreclose rivals has been one of the main points of concern in antitrust investigations concerning retail MFNs. For example, in the abovementioned HRS decision, the FCO alleges that "the MFN clauses furthermore impede the market access of new competitors" (FCO 2013c, para. 160) through preventing access to cheaper offers through lower commissions or another strategy which is advantageous for the hotels. In this respect, FCO points to the example of Justbook, a new mobile reservation channel, which offered more advantageous terms to hotels but whose request for cheaper room offers was nevertheless refused due to the presence of retail MFNs protecting HRS.

Similar effects were also noted by the CMA which stated that its analysis "suggested that wide MFNs will make it hard for an entrant to adopt a differentiated, low-premium entry strategy" (CMA 2014, 8.69). As evidence of this claim, the CMA examined the failure to enter the market by Covea SGAM. According to Covea SGAM's market analysis, the downside risks were too high to justify level of investment required to launch a full scale operation in the UK unless it could enter under a differentiated business model. The undertaking was barred from pursuing a low-price strategy through the existence of wide MFNs, and did not enter the market as it found differentiation based on marketing to be unpromising.

The exclusionary effects of retail MFNs are indirectly supported by the dynamics of multi-sided markets where they are often utilized. Multi-sided markets are 
characterized by indirect network effects whereby the demand faced by the platform operator on one side is dependent on the number of users on the other side (Samuelson et al. 2012, p.1). The presence of indirect network effects has been argued to make market entry more difficult, therefore leading to highly concentrated structures in the case of multi-sided markets. (OECD Report, p.98, 115; Samuelson et al. 2012, p.1) In the same vein, Evans (2013) emphasizes the importance of reaching a "critical mass" of users for the viability of a platform business. According to the author's definition "critical mass is the amount of demand on both sides that is sufficient to generate positive feedback effects" (Evans 2013, p.18). Platforms that reach this level are able to trigger positive feedback effects which propel them towards growth. However, "based on casual evidence it appears that most new platforms do not make it through this initiation phase" (Evans 2013, p.19).

Against this background, the possibility of product differentiation emerges as one of the main ways to facilitate entry into a multi-sided market. Indeed, as Evans states "product differentiation is a key reason why many industries with multi-sided platforms have multiple competitors even though indirect network effects and sometimes economies of scale would seem to propel them to monopolies" (Evans 2013 , p.8). As a result, the exclusionary effect/barriers to entry created by the propensity of retail MFNs to preclude differentiation based on a low cost/low price model could be very significant in a multi-sided setting.

\section{Facilitating collusion}

MFNs by their nature will increase price transparency in a given marketplace, depending as they do on the exchange of pricing information (directly or indirectly). In the case of MFNs with auditing rights, the dissemination of competitively sensitive information is likely to be even more widespread. The very existence of MFNs can also be used as a signaling strategy between horizontal competitors to communicate that they do not intend to engage in aggressive price competition, particularly if a large proportion of the market becomes subject to similar MFNs. In addition to achieving price transparency, as identified by Butz (1990), the use of MFN provisions may act as a device by cartel members against customers who may hold out against price increases and frustrate the cartel through postponing orders and waiting until one party offers a discount.

Butz (1990) explains this effect in reference to the MFN provisions used in the U.S. market for turbine generators in the 1960 and 1970s, which were ultimately stopped by the Justice Department, as explained in reference to United States $v$. General Electric Co. The author points out that the adoption of MFN provisions by GE and Westinghouse had a significant stabilizing effect on the market, eliminating the price competition which formerly existed in the market despite its oligopolistic structure. Butz (1990) explains that the MFN provisions may have furthered price stability not only through making it more costly for the firms to offer discounts but also leading the customers to refrain from postponing orders in the present as they could theoretically still benefit from future discounts. The significance of this theory is highlighted as follows: "In the conventional explanation, best price provisions 
enhance cooperation between firms at each point in time. Here the provisions enable a single cartel to collude with itself across time. Best-price provisions could be commitments to industry rivals, yet they could also serve as commitments to buyers" (Butz 1990, p. 1071).

In the abovementioned United States v. General Electric Co, the (traditional) retroactive MFN clauses used by GE and White Westinghouse were challenged by the DOJ based on the grounds that the MFN clauses constituted a facilitating practice for collusion regarding the prices of turbine generators along with various other practices including publication of similar and extensive price books. As a result of the DOJ's action, the companies agreed to a consent decree whereby they voluntarily dropped the MFN clauses and committed not to publicly disseminate price data. In a similar vein, in E.I. Du Pont De Nemours \& Company v. Federal Trade Commission, Dupont and Ethyl Corp, the two largest producers in the market for antiknock additives, used a combination of potential facilitating practices including advance notices to customers and the press regarding price increases, and traditional MFN clauses. While the FTC condemned the use of MFN clauses under Sect. 5 of the FTC Act, this finding was reversed by the Second Circuit, which noted, inter alia, that Ethyl had adopted the MFN clause while it was the only producer in the market. The court used this finding to argue that the MFN clause must have been adopted with a pro-competitive purpose as opposed to facilitating collusion.

Retail MFN clauses have been associated less with collusion in the antitrust scrutiny of such cases in comparison to their unilateral effects in terms of dampening competition and exclusion of rivals. The notable exception in this regard is the $e$-books cases in the US and EU which concerned a rather unique set of facts. In the relevant case, the publishers under investigation were alleged to have engaged in a horizontal concerted practice to switch to an agency system and refrain from distributing e-books through a distributor/reseller system. The European Commission alleged that the publishers exchanged information, directly and through Apple, as to whether to switch to an agency model with Apple and the key terms of the agency arrangements, including retail MFN clauses. The publishers were concerned with Amazon's resale of e-books below the wholesale prices as a loss leader to facilitate the sale of its Kindle device, which hurt the publishers' profits in other channels such as printed books (Johnson 2014).

In its preliminary assessment, the Commission reasoned that the mutual use of such retail MFN clauses would have functioned as a "commitment device" as they could have meant significantly lower revenues for the publishers unless they put a stop to lower pricing by Amazon or other retailers proceeding under the "resale" model. (Case COMP/39.847-E-Books 2013a, para. 38) Apple was implicated in the concerted action between the publishers as it made the concerted practice possible by disclosing information to each of the retailers about the others' intentions. The resulting commitments included a ban on the use of retail MFNs, as well as "wholesale" MFNs (concerning the publishers' wholesale prices to retailers) and "commission/revenue share" MFNs (concerning the level of commission/ revenue share received by a retailer under the agency model) (Case COMP/ 39.847-E-Books 2013a, paras. 102, 138). 
This case was also subject to antitrust enforcement in the US, with the investigation reaching a similar conclusion. In United States v. Apple, Inc., the federal district court held after a full trial on the merits that Apple's pricing provisions with e-book publishers, the same ones mentioned above, violated US competition laws. (The district court's decision is currently under appeal.) The court found that the publishing agreements between Apple and five publishing houses constituted a per se illegal price-fixing conspiracy, orchestrated by Apple. The court found that the effect of the retail MFNs in this scheme was to incentivize the publishers to force Amazon and other e-book sellers to accept an agency business model that allowed the publishers to raise retail prices. In the litigated case against Apple, the court did not need to address the legality of MFNs as a general matter, focusing as it did on the issue of the alleged price-fixing conspiracy, of which the MFN was merely one part. However, as part of the overall investigation, the Department of Justice obtained consent decrees from the publisher defendants that require the publishers to terminate any contracts with e-book retailers that contain price MFNs. As in Europe, the publishers were also prohibited from entering into e-book retailer agreements that contain MFNs for 5 years. A federal district court approved these consent agreements, concluding that the interoperation of the agency contracts, retail price MFNs and the collusive behavior together constituted a violation of the antitrust laws, though any one of those acts did not necessary violate the law by itself.

\subsubsection{Factors presenting significant anti-competitive concerns}

As provided above, the anti-competitive potential of MFN clauses may be magnified depending on market dynamics. In addition to providing a solid theoretical background, through setting out such specific factors, a model guideline would be able to concentrate the resources of competition authorities on areas of increased risk and also provide guidance on what to avoid for businesses and practitioners. This would be particularly useful for general legal practitioners or officials of undertaking looking for concrete guidance as opposed to theory. As a result, below we present a discussion regarding certain characteristics of MFN clauses with that have been singled out as presenting a higher chance of anti-competitive effects.

Where more than one of the below factors are present together, or the magnitude of one anti-competitive factor (such as very high market shares of the parties, or particularly high penalties for discounts), in principle, it will be difficult for procompetitive effects to balance the negative effects on competition. Based on the existing academic literature as well as the positions taken by the authorities in a variety of jurisdictions which are outlined above, the following factors may be set out as presenting particularly high risks to competition:

\section{MFN-Plus provisions}

MFN-plus provisions go beyond guaranteeing a buyer equally advantageous terms as those offered to other buyers, but guarantee that the terms offered to the relevant buyer will be better than those offered to other customers. MFN-plus provisions are more likely to result in harm to consumers (Salop and Scott Morton 
2013) since they are likely to involve instances where a buyer may even accept higher costs of input in order to impose even greater costs on its rivals and therefore gain a competitive edge.

As MFN-plus provisions are centered on increasing the relative costs of competitors, the associated risks of exclusionary effects on competitors will be particularly high. Furthermore, MFN-plus provisions are unlikely to satisfy the condition of restricting competition to the extent that is indispensable for the attainment of the proposed efficiencies such as provided under Article 101(3) of the TFEU. This is because any of the efficiencies outlined above could likely be achieved through a regular MFN clause.

\section{Retroactive MFN clauses}

In comparison to contemporaneous MFN clauses where the seller is only responsible for matching lower prices it offers which are contemporaneous with the MFN-holder's purchase (or at least within a relatively short time frame), retroactive MFN clauses (where the seller must provide the same low price to past sales) may pose greater risk for competition. In effect, the more "retroactive" an MFN clause becomes, the greater the number of offers which will be covered-and therefore the greater the "tax" on a discount and the resulting effect in terms of dampening competition. Similarly, the ability of cartel members to stabilize the cartel, or a monopolist to increase its bargaining power vis-à-vis buyers who hold out for better prices will be dependent on the MFNs being retroactive.

That said, retroactive MFNs may also result in important efficiencies. For example, the potential for MFN clauses to effectively remedy the problem of customers holding out for better terms to the extent that a business may not reach the critical mass of customers to launch itself depends on the retroactivity of the MFN.

As a result, an analysis on retroactive MFN clauses will require a balancing of these potentially conflicting effects.

\section{MFN clauses with penalties}

While a penalty may provide certain benefits in terms of assuring compliance, given the increase in the disincentive to discount-and therefore the dampening effect on competition - as a result of the penalty, it is unlikely that this would be enough to justify the inclusion of a penalty.

\section{Large supplier/large buyer with market power/highly concentrated markets}

Predictably, the risks to competition are higher where the relevant parties to an MFN arrangement have high market shares (Salop and Scott Morton 2013). This is true for both the risks of collusion and price rigidity in the market (where the market share of the supplier will be particularly relevant) as well as the risk of exclusionary effects on the competitors of the buyer (where the market share of the buyer will be particularly relevant) (Salop and Scott Morton 2013, Jacobson and Weick 2012). As 
a corollary, a high level of concentration in the relevant market similarly exacerbates the anti-competitive effects, particularly the risk of collusion in the upstream market. Conversely, where there is a relatively high number of suppliers, both the chances for a buyer to exclude competitors through raising their cost of input and the ability of suppliers to achieve a collusive outcome are significantly lessened.

In light of the above, a guideline could provide cut-off market shares where an MFN clause would be presumed anti-competitive, shifting the burden of proof on the relevant undertakings to prove otherwise. If such cut-off market shares are provided, they should be very high to be on the conservative side.

\section{Wide-spread use of MFN clauses in a market}

The wide-spread use of MFN clauses in an industry in such a way that parallel restraints cover a substantial part of the market would also result in cumulative effects which magnify the anti-competitive effects of MFN clauses (Salop and Scott Morton 2013; Cernak and Chaiken (2013)). This is particularly true for risks of collusion and price rigidity. Where all or a substantial part of the suppliers in a market commit to making it more costly to engage in discounts, this would considerably stabilize any potential collusive arrangements. Similarly, the mutual use of MFN clauses would be more effective in terms of communicating a general intent to refrain from engaging in price competition among market participants. Even without collusion, the use of MFN clauses in a way that they cover a substantial part of the market could result in significant price rigidity through making discounts more unlikely with respect to a substantial amount of transactions in the relevant market.

The enforcement trends toward MFN clauses demonstrate the significance of parallel usage of MFN clauses. In particular, the Commission's enforcement efforts such as the theater digitalization case, and the $e$-books case focus on the cumulative effect of parallel usages of MFN clauses in the relevant industry. The FCO has also noted the industry-wide use of retail MFN clauses in its $H R S$ decision, stating that the use of MFNs by different platform operators strengthen the anti-competitive effects in the market. Indeed, the FCO noted that given the combined market shares of HRS, Booking.com and Expedia, the MFN clauses covered nearly $90 \%$ of the relevant market (FCO 2014d, para. 163).

In parallel with the above, a model Guideline could provide a cut-off where MFN clauses would be presumed anti-competitive if parallel networks of MFN clauses cover a certain percentage of the market.

\section{Wide retail MFNs}

In the above mentioned PMI Market Investigation by the CMA, the authority reasoned that, while networks of narrow MFNs (covering only the direct channel of the supplier) could also potentially have the effect of softening competition between retailers where suppliers conduct significant amounts of sales through the direct channel, in general wide MFNs (extending to sales over other platforms/resellers as 
well) had a stronger negative effect on inhibiting price competition between retailers. Similarly, wide retail MFNs resulted in exclusionary effects toward existing rivals and would-be entrants through precluding product differentiation through a low-cost/lowprice model. Wide retail MFNs were also found to result in relatively low level of additional efficiencies over and above those produced by narrow retail MFNs in terms of engendering consumer trust or prevention of free riding (CMA 2014).

While these dynamics could change based on the market in question, the above findings suggest that wide retail MFNs generally pose greater competition law concerns. $^{11}$

\subsection{Efficiencies and justifications}

We argue that a model guideline should discuss the particular efficiencies which can be achieved through the use of MFN clauses and the specific contexts where MFN clauses may have particularly strong pro-competitive effects. Particularly, in the case of EU law, highlighting potential pro-competitive effects would provide guidance for the first element of individual exemption analyses under Article 101(3) of the TFEU where the awarding of an individual exemption is predicated on the relevant agreement's "contributing to improving the production or distribution of goods or to promoting technical or economic progress."

The existing academic literature provides a consensus as to certain benefits which may be achieved through the use of MFN clauses.

\section{Efficient contract structures/encouraging relationship-specific investments}

In cases of long term contracts where future market conditions are hard to predict, both the buyer and supplier are legitimately concerned about being locked into a deal with potentially disadvantageous terms (Salop and Scott Morton 2013). The adoption of a (traditional) MFN clause solves this problem through introducing greater flexibility to the contractual relationship. Through being assured that it will not receive worse terms than the future customers of the relevant supplier, who will be better informed about the market conditions then prevailing, the buyer mitigates the risks associated with unpredictability and therefore may be willing to engage in deals which may otherwise not take place. The supplier also benefits as it will likely be able to offer higher prices than it otherwise would and therefore decrease its own risks of being locked into a disadvantageous deal.

The combination of a long-term contract with an MFN clause also prevents opportunistic behavior by a transaction party after the other undertakes a

\footnotetext{
${ }^{11}$ Other examples of antitrust cases where there has been a differentiation between narrow and wide retail MFNs are the investigation by a variety of national competition authorities concerning the retail MFN clauses used by the online hotel reservation platforms Booking.com and Expedia. On April 21, 2015, the French, Italian and Swedish competition authorities accepted binding commitments from Booking.com whereby Booking.com agreed to drop its retail MFN clauses in regard to conditions offered through other online reservation platforms. The hotels would also be able to offer better sales conditions through offline channels such as their reception desks. However, Booking.com retained its "narrow retail MFN" vis-à-vis the conditions offered through the hotels' own webpage. See http://news.booking.com/ bookingcom-announces-support-of-new-commitments-in-europe.
} 
relationship specific investment. This way, the buyer is assured that it will not be disadvantaged vis-à-vis other buyers as a result of the commitment it has made through undertaking a relationship-specific investment, while at the same time retaining price flexibility in the relationship to adapt to future market conditions.

Various papers studying the use of MFN clauses or similar structures in natural gas contracts support the above discussion. Mulherin (1986) who has analyzed the use of MFN clauses and take-or-pay provisions in the natural gas industry based on contracts in the 1940-1954 period concludes that the best explanation for the use of these provisions in the given case seems to be a desire to minimize transaction costs through introducing a contractual structure which prevents opportunistic behavior by the pipeline while still allowing "timely adjustment" to changing market conditions (Mulherin 1986, 112-113). Crocker and Lyon (1994) similarly provide empirical support on the use of MFNs to introduce price flexibility in long term contracts with high and relation-specific fixed costs without risking opportunistic behavior, as opposed to such clauses being motivated by a desire to facilitate coercion. ${ }^{12}$ Canes and Norman (1986) also describe the role of MFN clauses in the natural gas industry in a similar manner: long term contracts encourage investments with large fixed-costs, while the MFN clauses in turn provide a low-cost mechanism to adapt the contract prices to market conditions.

Baker and Chevalier (2013) and Van der Veer (2013) note that MFN clauses are in general an effective way for a buyer undertaking a relation-specific investment that it will not be the subject of subsequent opportunistic conduct and therefore be in a competitive disadvantage, without a specific reference to a long term contract. As long as the MFN protection stays in effect, the investing party is assured that it will be treated equally with any other buyer.

\section{Reduced transaction costs/agreement continuity}

Traditional MFNs may lead to efficiencies by reducing the transaction costs associated with bargaining. The potential of MFN clauses to reduce transaction costs is generally recognized (Baker and Chevalier 2013; Van der Veer 2013). Returning to the healthcare example, it is expensive and time-consuming for insurers and medical providers to negotiate the complex pricing of medical services. Periodically, difficult negotiations even lead to contracts expiring before a new one is in place, leading to disruptions in medical care for patients. The same disruptions have occurred in the television market (Samuelson et al. 2012). An MFN could reduce the frequency of bargaining and therefore its associated costs. In effect, the buyer with the MFN is free-riding on the bargaining costs of the other buyers. In markets with volatile, complex or uncertain pricing, the reduced transaction costs could be significant and, again, potentially passed onto consumers (Cernak and Chaiken (2013)). Overall, where the pricing parameters are especially complex and therefore bargaining costs are especially high, MFN clauses can reduce costs.

\footnotetext{
${ }^{12}$ Based on Crocker and Lyon (1994)'s data, in the context of the natural gas sector which is characterized by low market power for suppliers (i.e. well operators) and high market power for buyers (i.e. gas pipeline operators), the use of MFN clauses increases as the number of buyers increase even though the use of MFN clauses should have been more prominent in more concentrated settings if the main rationale for adoption was to facilitate collusion.
} 


\section{Prevent delays/hold-outs}

Baker and Chevalier (2013) also describe a scenario in which a (traditional) MFN could reduce transaction delays, by resolving what could be termed the "hold out" problem, or by discouraging buyers from delaying purchase in hopes of a better deal. The authors describe a hypothetical in which a land developer wants to build a project that requires a minimum number of landowners to sell their property. Each landowner should want to be the last to sell, since that will increase their bargaining leverage, which may lead to hold-outs. An MFN would resolve this by guaranteeing to earlier sellers that they will receive the best price offered to the later sellers.

Similarly, where market dynamics are such that buyers may be tempted to holdout in hopes of receiving better terms in the future, the use of an MFN clause can be used to mitigate such hold-out problems through guaranteeing equally advantageous terms to those making early commitments (Baker and Chevalier 2013; Van der Veer 2013; Salop and Scott Morton 2013). The efficiencies created by mitigating hold-out problems may be particularly high where an initial level of early purchases is necessary for subsequent network effects or high-cost relation-specific investments (Salop and Scott Morton 2013).

\section{Platform and brand value}

An additional justification for MFNs discussed in the literature relates to encouraging investments in a brand or platform. Samuelson et al. (2012) note that "in two-sided markets, the structural integrity of the platform is paramount" (Samuelson et al. 2012, p.3). However, the users of the platform can affect its value and reputation. MFNs could prevent the value of the platform from being damaged through the appearance of disadvantageous offers, or some other disadvantage for using the relevant platform. Samuelson et al. (2012) provide the example of merchants disadvantaging the use of a payment card which may significantly affect the popularity of the relevant payment card. The authors further argue that given the indirect network effects in multi-sided markets, the reductions in the number of customers occurring as a result of such disadvantages would further reduce the value of the platform for the customers on the other side (i.e. the merchants in the above example).

The appearance of a disadvantage could be particularly damaging to the business model of certain platforms such as online travel agents or price comparison websites which were at issue in certain important antitrust investigations regarding retail MFNs in Europe. Since such platforms create value for consumers through reducing transaction costs, including those of searching at other sites, consumers may no longer be willing to use the platform if they perceive that they still need to engage in further research to find better offers. The price comparison websites investigated in the CMA's Private Motor Insurance Market Investigation tried to rely on this defense, stating that "if consumers did not have confidence that PCWs were comparing prices, consumers might stop using them altogether" (CMA 2014, 8.90).

This justification was accepted only to a limited degree by the CMA. The authority found that "narrow" retail MFNs ensuring that price comparison website 
would not receive less advantageous quotes than offered in an insurer's own website were pro-competitive in that they engendered consumer trust and reduced the need for consumers to visit insurers' own websites (CMA 2014, 8.97). However, the authority took the position that wide-MFNs (i.e. those ensuring the best quote across all platforms) provided little additional value. The CMA reasoned that, in that particular case, a significant number of users already tended to multi-home to a certain extent (i.e. search in multiple PCWs to compare offers).

\section{Prevention of free-riding}

In cases involving retail MFN clauses, platform operators have made the argument that retail MFN clauses, which ensure the platform operator that the retail price offered by the supplier is at least as advantageous as that which it offers on other platforms, may create efficiency through preventing low cost/low quality platform from free-riding on the marketing/promotion activities and high quality services by other platforms.

In its investigation of the online hotel booking platform, HRS, the German FCO, did not accept this defense by the platform as it reasoned that the losses due to freeriding were likely to be low given that the online platforms' investments were generally not contract-specific (FCO 2013c, para. 204). The FCO posited that noncontract investments in quality would not be lost as a result of free riding since they improved the general image of the platform (FCO 2013c, para. 205). The agency also ruled that the "billboard effect" whereby hotels exploit the portal to then attract the booking to their own websites via cheaper rates would not be a serious concern for the German market.

It is important to note that, despite taking this position in the specific case of HRS, the FCO accepted that retail MFNs could improve distribution through eliminating free riding, thereby fulfilling the first condition under an individual exemption analysis under Article 101 (3) TFEU in its Vertical Restraints in the Internet Economy background paper. In particular, it described the risk of free riding in the following way:

"Free riding activities by dealers or service providers that also use the services of a platform could take the following form: the dealers or providers could use the investments made by the platform, which include contract-specific investments such as the editing of their offer and unspecific investments such as the listing and sorting of offers ('bulletin board effect') and investments into the popularity of the platform which increase visitor traffic and enhance consumer trust. Before a business transaction is concluded they could induce their customers, e.g. end consumers, to go to their own internet shop or another sales channel with a lower commission, thus avoiding the payment of the commission due for the services provided by the platform" (FCO 2013a, p.25)

The PCWs in the CMA's PMI Market Investigation also used the prevention of free riding as a justification for retail MFNs. The CMA did not find the prospect of free riding by other platforms to be a significant concern therefore it did not find that 
wide-MFNs had a pro-competitive contribution in this regard (CMA 2014, 8.106). With respect to narrow-MFNs, the agency reasoned that there was some risk of free riding by PMI providers themselves, especially as the search results indicated the provider of the most advantageous quote. In this respect, the authority speculated that this risk could be dealt with through alternative means such as "quote poaching clauses" and alternative charging models, but ultimately did not see the need to reach a final position as it already refrained from condemning narrow-MFNs (CMA 2014, 8.100-101).

\section{Lower prices}

In certain specific circumstances, the MFN might operate to lower average market prices. For example, as Samuelson et al. (2012) note, in markets where a small buyer might be able to secure a lower price than large buyers (perhaps because the seller has marginal excess capacity), and prices are not transparent, an MFN might allow the lower price to diffuse further across the market. Note, however, that this requires that it would be profit-maximizing for the seller to offer the lower price to the small buyer, knowing that it will then have to offer the lower price to the buyer with the MFN as well. In the same vein, where it is the case that a smaller buyer, rather than a large one, which is protected by the MFN, the "tax" on discounting would be relatively small and therefore the supplier could likely still provide discounts to large buyers with greater market power, which would be passed on the small buyer as a result of the MFN

\subsection{Safe harbors}

As discussed above, one of the most important contributions to be provided by a guideline would be to identify certain safe harbors where the use of MFN clauses would be presumed legal. The following factors are good candidates for safe harbors:

\section{Lack of market power/low market share}

The use of MFN clauses is unlikely to present competition law concerns where the parties to an MFN lack market power (Salop and Scott Morton 2013). As provided above, where the supplier provides a discount to any particular party, the existence of MFN arrangements forces the supplier to provide the same discount to the party protected by the MFN - thereby acting as a disincentive for such selective reductions in price. However, this disincentive is likely to be low where the relevant buyer only has a small market presence. In other words, the "disincentive" created by the need to offer a discount to a small player with a relatively low level of purchases would be less likely to prevent suppliers from offering discounts altogether. In fact, where MFN clauses are only awarded to small market players, this may well have the overall effect of lowering the prices in the downstream market through ensuring that small players also enjoy the discounts provided to larger firms. Where the supplier also constitutes a small share of the supply in the market, this would make the prospect of any negative effects on the overall price 
level in the relevant market even more unlikely, as alternative suppliers who are not bound by similar arrangements could meet the excess demand and offer discounts to capture business from the supplier bound by the MFN.

In light of this consideration, a model guideline should provide that MFN clauses are to be considered legal where the market share of both the buyer and seller are below a certain threshold. The exception to such a safe harbor would be where widespread parallel usages of MFN clauses by many market players add up to covering a substantial amount of the market. ${ }^{13}$ In such a case, even where the disincentive on discounting created by individual arrangements may be small, the combined effect may still be sufficient to promote price rigidity in the relevant market.

\section{Unconcentrated markets}

Similar to the above, MFN clauses are unlikely to lead to harms to competition where the level of concentration in both markets is low (Salop and Scott Morton 2013). As such, a safe harbor similar to the above could also be designed based on concentration levels of the relevant markets (e.g. in terms of Herfindahl-Hirschman Index or HHI figures), ${ }^{14}$ or a safe harbor based on a combination of market share and level of concentration in the market could be envisioned.

Similar to the above, the safe harbor treatment would need to be removed where widespread parallel usages of MFN clauses end up covering a substantial part of the market.

\section{Conclusion}

As discussed above, the effects of MFN clauses in the level of competition in the relevant markets and the resulting antitrust consequences are particularly complex. This complexity is in turn reflected in the case law of the courts and antitrust enforcement agencies, which have dealt with the resulting antitrust concerns based on the dynamics of each case as they have found them. Especially coupled with the scarcity of relevant precedent in many jurisdictions, this makes a case-by-case approach disadvantageous from the perspective of businesses seeking to utilize MFN clauses in their agreements, and desiring to reach legal certainty regarding the relevant antitrust consequences.

\footnotetext{
13 This exception would be similar in character to Article 6 of VBER which provides that "the Commission may by regulation declare that, where parallel networks of similar vertical restraints cover more than $50 \%$ of a relevant market, this Regulation shall not apply to vertical agreements containing specific restraints relating to that market".

14 To assess the concentration level via the HHI levels, one would need to calculate the squares of the individual market shares of all the firms in the market and add the relevant figures. For instance, the European Commission considers that in a market where the HHI is below 1,000, the market would not be highly concentrated (please refer to the Guidelines on the Assessment of Horizontal Mergers under the Council Regulation on the Control of Concentrations Between Undertakings).
} 
As defended above, a guideline that brings together the accumulated guidance regarding the competitive consequences of MFN clauses based on both the legal cases from different jurisdictions and the economic effects of MFNs discussed in academic literature could provide important benefits. Particularly, such a document could provide practical guidance and a level of legal certainty through proposing safe harbors as well as noting the particularly risky situations to be avoided.

In the above sections, we provide the outline of such a guideline document. While there could be variations in terms of structure and content, we believe that secondary legislation which can provide the desired level of guidance should generally cover the point outlined in Section II above. The creation of safe harbors is particularly important since, as shown above, MFN clauses are often adopted with pro-competitive purposes in mind and the negative effects on competition are unlikely to be significant in situations where neither the supplier nor the buyer possess market power, and the effects of individual MFN arrangements are not magnified through networks of similar arrangements covering significant parts of the relevant market. Furthermore, through providing a comprehensive discussion of potential pro-competitive and anti-competitive effects of MFNs, the existence of a comprehensive guideline could significantly aid case-by-case analyses even where no safe harbors apply.

\section{Compliance with ethical standards}

Conflicts of interest The authors declare that they have no conflict of interest.

Statement on human rights and welfare of animals This article does not contain any studies with human participants or animals performed by any of the authors.

Open Access This article is distributed under the terms of the Creative Commons Attribution 4.0 International License (http://creativecommons.org/licenses/by/4.0/), which permits unrestricted use, distribution, and reproduction in any medium, provided you give appropriate credit to the original author(s) and the source, provide a link to the Creative Commons license, and indicate if changes were made.

\section{References}

Aguzzoni, L. et al. (2012). Can 'fair' prices be unfair? A review of price relationship agreements, L.E.A.R. (Laboratorio di economia, antitrust, regolamentazione), http://www.oft.gov.uk/shared_oft/ research/OFT1438.pdf. Accessed 8 April 2014.

Baker, J., \& Chevalier, J. (2013). The competitive consequences of most-favored-nation provisions. Antitrust, 27(2), 20-26.

Boik, A., \& Corts, K. S. (2013). The effects of platform MFNs on competition and entry, Working Paper.

Butz, David A. (1990). Durable-good monopoly and best-price provisions. The American Economic Review, 80(5), 1062-1076.

Canes, M. E., \& Norman, D. A. (1984). Long-term contracts and market forces in the natural gas market. The Journal of Energy and Development, 10(1), 73-96.

Cernak, S., \& Chaiken, T. (2013). Most favored nation's clauses, practical law company. http://www. schiffhardin.com/Templates/media/files/publications/PDF/Cernak_Chaiken_Most-Favored-NationClauses_20130311.pdf. Accessed 8 April 2014.

Crocker, K., \& Lyon, T. (1994). What do 'facilitating practices' facilitate? An empirical investigation of most-favored-nation clauses in natural gas contracts. Journal of Law \& Economics, 37(2), 297-322. 
Dennis, A. (1995). Potential anticompetitive effects of most favored nation contract clauses in managed care and health insurance contracts. Annals of Health Law, 4(1), 71-85.

Evans, D. (2013). Economics of Vertical Restraints for Multi-Sided Platforms, http://ssrn.com/abstract= 2195778.

FCO (Federal Cartel Office). (2013a). Vertical restraints in the internet economy: meeting of the working group on competition law.

Jacobson, J. \& Weick, D. (2012). Contracts that reference rivals as an antitrust category, The Antitrust Source, 1-11 April 2012, http://www.americanbar.org/content/dam/aba/publishing/antitrust_source/ apr12_full_source_4_26f.authcheckdam.pdf. Accessed 8 April 2014.

Johnson, J. P. (2014). The agency model and MFN Clauses, SSRN: http://ssrn.com/abstract=2217849

Mulherin, J. H. (1986). Complexity in long-term contracts: an analysis of natural gas contractual provisions. Journal of Law Economics and Organization, 2(1), 105-117.

Oxera (2014). Most-favored nation clauses: Falling out of favour? available at http://www.oxera.com/ Latest-Thinking/Agenda/2014/Most-favoured-nation-clauses-falling-out-of-favour.aspx

Salop, S., \& Scott Morton, F. (2013). Developing an administrable MFN enforcement policy. Antitrust, 27(2), 15-19.

Samuelson, M., Piankov, N., \& Ellman, B. (2012), Assessing the effects of most-favored nation clauses, aba section of antitrust law spring meeting 2012, http://www.analysisgroup.com/uploadedfiles/ content/insights/publishing/samuelson_mfn_springaba_2012.pdf. Accessed 26 June 2015.

Scott Morton, F. (1997). The strategic response by pharmaceutical firms to the medicaid most- favoredcustomer rules. The RAND Journal of Economics, 28(2), 269-290.

Scott Morton, F. (2012). Contracts that reference rivals (Speech 5 April 2012), http://www.justice.gov/atr/ public/speeches/281965.pdf. Accessed 8 April 2014.

Stenger, S. (1989). Most-favored-nation clauses and monopsonistic power: an unhealthy mix? American Journal of Law and Medicine, 15, 111-128.

Van der Veer, J. P. (2013). Antitrust scrutiny of most-favoured-customer clauses: an economic analysis. Journal of European Competition Law and Practice, 4(6), 501-505.

\section{Cases and decisions}

Antitrust: Commission opens formal investigation into Amazon's e-book distribution arrangements, Press Release, European Commission, http://europa.eu/rapid/press-release_IP-15-5166_en.htm, Accessed June 12, 2015.

Amazon. (2015). Press release by the European commission IP/15/5166, http://europa.eu/rapid/pressrelease_IP-15-5166_en.htm. Accessed 23 June 2015.

Case COMP/39.847 - E-books (2013a). Commitments Decision C(2012) 9288 OJ C 73/07 (addressed to Hachette Livre, HarperCollins, Verlagsgruppe Georg von Holtzbrinck, Simon and Schuster, and Apple).

Case COMP/39.847 - E-books. (2013b). Commitments decision of 25 July 2013 (addressed to Penguin).

CMA. (2014). Final report, private motor insurance market investigation, https://assets.digital.cabinetoffice.gov.uk/media/5421c2ade5274a1314000001/Final_report.pdf. Accessed 22 December 2014.

E-books. (2012). Antitrust: commission accepts legally binding commitments from Simon \& Schuster, Harper Collins, Hachette, Holtzbrinck and apple for sale of e-books, Memo, European Commission, http://europa.eu/rapid/press-release_MEMO-12-983_en.htm. Accessed 30 December 2014.

E.I. Du Pont De Nemours \& Company v. Federal Trade Commission, Ethyl Corporation, v. Federal Trade Commission, 729 F.2d 128 (2nd Cir. 1984).

FTC v. RxCare of Tennessee, 121 F.T.C. 762 (1996).

FCO. (2013b). Online hotel portal HRS's "best price” clause violates competition law_proceedings also initiated against other hotel portals, http://www.bundeskartellamt.de/SharedDocs/Meldung/EN/ Pressemitteilungen/2013/20_12_2013_HRS.html. Accessed 9 April 2014.

FCO. (2013c). Case no. B 9 - 66/10 - HRS, decision of 20 December 2014, http://www.bundeskartellamt. de/SharedDocs/Entscheidung/EN/Entscheidungen/Kartellverbot/B9-66-10.pdf?_blob=publication File\&v=3. Accessed 29 December 2014.

OECD Policy Roundtables-Two-Sided Markets ("OECD report”). (2009). http://www.oecd.org/daf/ competition/44445730.pdf.

OFT. (2014). Hotel online booking: Decision to accept commitments to remove certain discounting restrictions for Online Travel Agents, OFT1514dec. 
Pay TV. (2004). Press release by the European commission IP/04/2004, http://europa.eu/rapid/pressrelease_IP-04-1314_en.htm. Accessed 9 April 2014.

Ruhrgas/Gazprom. (2005). Press release by the European Commission IP/05/710, http://europa.eu/rapid/ press-release_IP-05-710_en.htm. Accessed 9 April 2014.

Theater Digitalization. (2011). Press release by the European commission IP/11/257, http://europa.eu/ rapid/press-release_IP-11-257_en.htm?locale=en. Accessed 9 April 2013.

United States of America v. Apple Inc., et al., 12 Civ. 2862 (DLC).

United States v. Blue Cross Blue Shield of Michigan, 809 F. Supp. 2d 665 (E.D. Mich. 2011).

United States v. Gen. Elec. Co., Case No. 28228, 1977 WL 1474 (E.D. Pa. Sept. 16, 1977). 